\title{
Strategic Climate Policy with Offsets and Incomplete Abatement: Carbon Taxes versus Cap-and-Trade*
}

\author{
Jon Strand \\ Development Research Group, Environment and Energy Team \\ The World Bank \\ Washington DC 20433, USA \\ Jstrand1@worldbank.org \\ and \\ Department of Economics, University of Oslo \\ Journal of Environmental Economics and Management, forthcoming, 2013
}

\begin{abstract}
:
This paper provides a first analysis of a "policy bloc" of fossil fuel importers which implements an optimal coordinated climate policy, faces a (non-policy) fringe of other fuel importers, and a bloc of exporters, and purchases offset from the fringe. We compare a carbon tax and a cap-andtrade scheme for the policy bloc, which in either case is accompanied by an efficient offset mechanism for reducing emissions in the fringe. The policy bloc is then shown to prefer a tax over a cap, since only a tax leads to a lower fuel export price and by more when the policy bloc is larger. Offsets are also more favorable to the policy bloc under a tax than under a cap. The optimal offset price under a carbon tax is below the tax rate, while under a cap and free quota trading the offset price must equal the quota price. The domestic carbon and offset prices are both higher under a tax than under a cap when the policy bloc is small. When the policy bloc is larger, the offset price can be higher under a cap. Fringe countries gain by mitigation in the policy bloc, and more under a carbon tax since the fuel import price is lower.
\end{abstract}

JEL Classification: Q31; Q38; Q54; Q58; H23

Key words: Climate policy; carbon taxes, cap-and-trade schemes; carbon emissions; strategic trade policy.

*I wish to thank, without implicating, Lawrence Goulder, Michael Toman, Ian Parry, Sauleh Siddiqui, and seminar participants at several institutions, plus two referees and an editor of this journal for helpful comments to previous versions. I in particular thank the arrangers of and participants at the Environmental Protection and Sustainability Forum at the University of Exeter, where the paper was first presented. The views expressed in this paper are those of the author only and should not be taken to represent those of the World Bank, its management, or member countries. 


\section{Introduction}

Today, only countries under Annex 1 of the Kyoto Protocol who have extended the validity of the Protocol up to 2020, at KOP18 in Doha, in December 2012, have policies which include formal climate policy targets. These countries might at later stages be joined by other highincome countries (including Canada, Japan and the U.S.), and perhaps also by some major emerging economies (among which China and South Africa have already signaled a willingness to impose greenhouse gas (GHG) pricing in the relatively near future). What seems not achievable, anytime soon, is a set of comprehensive and coordinated climate policies for all GHG emitters globally.

The countries with formal climate policies have agreed to binding emissions caps for the period 2013-2020; but these countries comprise less than 20 percent of global GHG emissions. Current policy includes two "offset" schemes. The most important of these is the Clean Development Mechanism (CDM), whereby abatement of carbon emissions, to comply with the overall cap, can be purchased from countries that do not have a climate policy. ${ }^{1}$ An objective of the CDM is to make it easier (and less costly) for emitters in the policy countries to abide by their emissions caps.

A climate policy could, alternatively, take the form of a carbon tax. No comprehensive carbon tax policy is so far used or seriously contemplated. ${ }^{2}$ Most observers see little difference between a climate policy involving a carbon tax, and a cap-and-trade (c-a-t) scheme with (expected)

\footnotetext{
${ }^{1}$ The other scheme is Joint Implementation which involves some Annex B countries purchasing offsets from other countries within this bloc.

${ }^{2}$ A few smaller nations, including the Scandinavian countries already from the early 1990s, have enacted unilateral and relatively comprehensive carbon taxes. But these countries constitute a too small fraction of global emissions to matter globally.
} 
emissions as under a tax. Some differences are still widely recognized; they all speak in favor of a tax over a cap. ${ }^{3}$

This paper focuses on differences between taxes and caps that have so far been less widely discussed. First, carbon taxes and c-a-t work differently when policy countries are net fossil fuel importers, and exporters behave strategically. Secondly, offset schemes may work differently under the two policies. Both differences, it is shown, tend to favor taxes over c-a-t for the countries implementing (or benefiting from) a climate policy.

In my model it is assumed that all countries can be split into two main groups, importers and exporters of fossil fuels. Most countries belong to the first group, including virtually all countries that may wish to establish a climate policy. The exporting group is smaller, notably the OPEC countries, and Russia including some previous Soviet republics. Importers consist of a "policy bloc” which pursues a climate policy (those Annex 1 countries that have extended the Kyoto Protocol); and a "fringe" with no policy (the "rest of the world"). The latter group acts without coordination, each perceiving no market power in fuel markets.

The producer and policy blocs are each assumed to coordinate their policies fully within their bloc, but not across blocs. The solution concept is static non-cooperative Nash Equilibrium (NE) in simultaneous strategies, for both models treated (in sections 2 and 3 respectively), in focusing

\footnotetext{
${ }^{3}$ Under uncertainty the effects differ as only emissions vary under a tax, and only the emissions price under a cap. From Weitzman (1974), when uncertainty takes the form that benefits (in terms of reduced climate change) of mitigation policy are less uncertain than costs in the short run (which, arguably, is the case in practice), a tax solution is preferred. See also Hoel and Karp (2001, 2002), Pizer (2002), and Karp and Costello (2004) for dynamic analyses. Secondly, the government's ability to recuperate income may be greater under a tax as many or most emissions permits are handed out for free to emitters under a cap. A third, politically important, difference is in terms of transparency of gains and losses to different affected parties. Under c-a-t it is easier to obscure these distributional implications. This may be a political reason why many countries seem to opt for c-a-t solutions, despite of the drawbacks pointed out.
} 
on short-run demand and supply relations. In both models the exporter sets a fuel export tax. In the first model, the policy bloc sets a carbon tax and offset price; and in the second model the policy bloc sets an emissions cap. Dynamic issues, in particular the exhaustibility of fossil fuels and the dynamics of climate change, are not studied. ${ }^{4}$ Sinn’s (2008) "green paradox" argument that carbon pricing could lead to increased emissions in the short run, is also not addressed. ${ }^{5}$

The policy bloc establishes an offset scheme for inducing abatement in the fringe, with two potential motivations. First, overall emissions can thus be further reduced, perhaps more cheaply than through mitigation in policy countries alone. Secondly, reduced fuel demand in the fringe may help reduce aggregate fuel demand and thus the fuel export price. Under c-a-t, I assume that the market for quotas is competitive with the same trading price for the policy bloc and fringe. Fringe country emitters are then paid an amount per abated emissions equal to the quota price facing policy country emitters. Under a carbon tax, it is less obvious how an offset market should be modeled. I assume that offsets are purchased from fringe countries by the policy bloc at a given offset price, set by this bloc, which clears the offset market in fringe countries. This offset price could, in principle, be either higher or lower than the carbon tax charged to policy bloc emitters. Importantly also, we assume no informational problems in implementing offsets and that all offsets are “additional”.

\footnotetext{
${ }^{4}$ This requires a dynamic model for a more complete analysis. A large literature here exists; see e g Bergstrom (1982), Karp (1984), Karp and Newbery (1991), Wirl (1994), Rubio and Escriche (2001), Salo and Tahvonen (2001), Rubio (2005), Liski and Tahvonen (2004); and more recently Karp and Zhang (2010) and Wirl (2012).

${ }^{5}$ The profile of future carbon taxes is here important. When the future carbon tax is expected to increase rapidly, an increase in the general level of carbon taxation could induce Sinn's paradox by raising emissions in the short run. Also, if climate policy partly implies supporting development of backstops for replacing fossil fuels, emissions may be worsened in the short run; see e g Strand (2007), Hoel (2010), and Ploeg and Withagen (2013).
} 
The preference for taxes over c-a-t for fuel importers has been shown in earlier papers by Berger, Fimreite, Golombek and Hoel (1992), and Berg, Kverndokk and Rosendahl (1997). Strand (2011) considers two fuels, one imported (oil) and one produced by consumer countries. Importers' oil demand is then somewhat elastic under a cap, allowing some rent extraction by importers. A tax here still dominates a cap for fuel importers. A possible objection to the current model is its static nature; this issue is elaborated further in the final section, with reference to follow-up work.

\section{Model 1: The Policy Bloc Sets a Carbon Tax}

\subsection{Basics}

Assume the following aggregate utility function related to fossil-fuel consumption for countries with a climate policy (the "policy bloc"):

$$
W_{1}=R_{1}-\frac{1}{2} \frac{\gamma}{h} R_{1}^{2}-p R_{1}-h c R-q_{1} \Delta R_{F},
$$

where $\gamma>0$, and $\mathrm{h}$ identifies the relative size of the policy bloc in total fuel demand, while the complement, 1-h, represents the relative size of the fringe. The policy bloc and fringe are assumed to be identical apart from their relative "sizes", represented by h. An increase in $h$ implies a proportional increase in both equilibrium fuel demand for given import prices, and in the externality cost experienced from GHG emissions. An interpretation is that all individuals' preferences are identical, and $\mathrm{h}$ represents the share of the global fuel-demanding population that resides in the policy bloc. While not by itself very realistic (and see comments at the end of section 5), this assumption facilitates the analysis of changes in relative sizes of policy bloc and fringe, a highly policy-relevant issue. 
$\mathrm{p}$ is the fossil fuel import price. $\mathrm{R}_{1}$ is the fossil-fuel consumption for the policy bloc, $\mathrm{R}$ is global fossil-fuel consumption, while hc represents the climate externality cost per unit of global fossil fuel consumption for policy bloc countries. Equation (1), and other demand and supply functions, take "linear-quadratic" forms standard in the literature (and as in related work by Strand (2011), Karp, Siddiqui and Strand (2013); and Wirl (2012)). We assume (with little loss of generality) that fossil-fuel importers produce no fuels, and that producer countries consume no fossil fuels and export all their production.

Let $\mathrm{R}_{\mathrm{F}}$ denote fuel consumption in the fringe. The last term in (1) represents an assumption that the countries in the policy bloc are able to induce a reduction of the fringe's fossil fuel consumption and thus carbon emissions, below the "business-as-usual" level, through a subsidy (or "offset price") $q_{1}$ to those units of fossil fuel consumption in the fringe with the smallest net productive yield (implying that abatement in the fringe is efficient). This term gives the net outlay by the policy bloc, related to incentive payments from the policy bloc to the fringe, given that all offsets in the fringe are purchased at price $q_{1}$, posted by the policy bloc. Such payments represent a mechanism under a carbon tax scheme that corresponds closely to an offset market under a c-a-t scheme (such as the CDM). $\mathrm{q}_{1}$ should however be interpreted somewhat differently from the trading price under a c-a-t scheme. In particular, it need not be identical to the domestic tax on emissions. Under c-a-t, market arbitrage will ensure identical carbon trading prices for all carbon units, which does not necessarily hold in the tax case.

In model 1 the policy bloc uses two instruments. First, it sets an excise tax, $t_{1}$, per unit of the imported fossil fuel. This leaves the consumer fuel price in these countries at $\mathrm{p}^{+\mathrm{t}_{1}}$. Fossil fuels are imported and consumed by many small competitive agents. The public demanding fossil fuels in this group of countries maximizes 


$$
V_{1}=R_{1}-\frac{1}{2} \frac{\gamma}{h} R_{1}^{2}-\left(p+t_{1}\right) R_{1}
$$

with respect to $\mathrm{R}_{1}$, yielding the demand level

$$
R_{1}=h \frac{1-p-t_{1}}{\gamma} .
$$

$\gamma \mathrm{h}$ is the inverse demand sensitivity of fossil fuels with respect to price in the policy bloc.

The "fringe" of fuel-importing countries with no climate policy (with subscripts F) has aggregate utility function (given no transfers from the policy bloc)

$$
W_{F 0}=R_{F 0}-\frac{1}{2} \frac{\gamma}{1-h} R_{F 0}{ }^{2}-p R_{F 0}-(1-h) c R,
$$

where subscript 0 denotes no transfers. (1-h)c is the climate-related externality of global fossil fuel consumption for the fringe. These countries in aggregate behave competitively. In the absence of transfers these countries would maximize

$$
V_{F 0}=R_{F 0}-\frac{1}{2} \frac{\gamma}{1-h} R_{F 0}{ }^{2}-p R_{F 0}
$$

with respect to $\mathrm{R}_{\mathrm{F} 0}$, yielding the first-order condition

$$
R_{F 0}=\frac{(1-h)(1-p)}{\gamma},
$$

where $\gamma /(1-h)$ is the inverse demand sensitivity for the fringe. The slope of the (global) aggregate demand function is $1 / \gamma$. 
The second instrument of the policy bloc is to pay a subsidy q $q_{1}$ per unit of offsets ("foregone fossil fuel consumption”) in the fringe; i. e., the difference between the fuel consumption that would have materialized had it not been for this subsidy, and actual fuel consumption in the fringe. ${ }^{6}$ The fringe thus reduces its fossil fuel consumption below the "benchmark" (6). The fuel price at the margin for the fringe equals $\mathrm{p}^{+} \mathrm{q}_{1}$, where the policy bloc makes up this difference through a subsidy to fringe fuel consumers. The induced fuel consumption in the fringe is then

$$
R_{F}=\frac{1-h}{\gamma}\left(1-p-q_{1}\right)
$$

The subsidy is assumed to be paid only on the amount of fuel consumption avoided in the fringe by the incentive payment, called $\Delta \mathrm{R}_{\mathrm{F}}=\mathrm{R}_{\mathrm{F} 0}-\mathrm{R}_{\mathrm{F}}$, given by

$$
\Delta R_{F}=\frac{1-h}{\gamma} q_{1}
$$

Aggregate fossil-fuel demand, from both blocs combined, is now

$$
R=R_{1}+R_{F}=h \frac{1-p-t_{1}}{\gamma}+(1-h) \frac{1-p-q_{1}}{\gamma}=\frac{1-p-h t_{1}-(1-h) q_{1}}{\gamma} .
$$

Assume a single (unified) producer country or region with aggregate utility function

$$
W_{2}=\Pi_{2}+s_{1} R-c_{2} R,
$$

where $\Pi_{2}$ is net profit of its petroleum producers, $s_{1} R$ is excise tax revenue for fuel exporting countries, while $\mathrm{c}_{2} \mathrm{R}$ denotes negative emissions externalities for the exporter bloc. Individual fuel exporters are price takes with profit functions

\footnotetext{
${ }^{6}$ This requires full additionality; see comments in section 5 .
} 


$$
\Pi_{2}=\left(p-s_{1}\right) R-p_{0} R-\frac{1}{2} \phi R^{2},
$$

where $\mathrm{p}_{0}$ is a lower bound on marginal fuel extraction cost. Maximizing (11) with respect to $\mathrm{R}$ yields the fossil-fuel supply function

$$
p=p_{0}+s_{1}+\phi R .
$$

$\phi(>0)$ represents the (inverse) supply sensitivity of petroleum output.

The externality cost of one unit of carbon emissions is hc for the policy bloc, and (1-h)c for the fringe. Individual fringe countries are small and ignore this factor in their own decisions. The global externality cost per fossil fuel unit equals $\mathrm{c}^{+} \mathrm{C}_{2}$, which would correspond to a Pigou tax imposed by a benevolent global regulator, given that markets are otherwise competitive.

Solving (9) and (12) for R and $p$ as functions of the tax parameters $t_{1}, q_{1}$ and $s$ yields

$$
\begin{gathered}
R=\frac{1-p_{0}-s_{1}-h t_{1}-(1-h) q_{1}}{\gamma+\phi}, \\
p=\frac{\gamma}{\gamma+\phi}\left(p_{0}+s_{1}\right)+\frac{\phi}{\gamma+\phi}\left(1-h t_{1}-(1-h) q_{1}\right) .
\end{gathered}
$$

We derive fuel demand for each bloc as functions of $\mathrm{s}, \mathrm{t}_{1}$ and $\mathrm{q}_{1}$, as follows:

$$
\begin{gathered}
R_{1}=\frac{h}{\gamma(\gamma+\phi)}\left[\gamma\left(1-p_{0}-s_{1}\right)-(\gamma+(1-h) \phi) t_{1}+(1-h) \phi q_{1}\right] \\
R_{F}=\frac{1-h}{\gamma(\gamma+\phi)}\left[\gamma\left(1-p_{0}-s_{1}\right)+\phi h t_{1}-(\gamma+\phi h) q_{1}\right] .
\end{gathered}
$$


A higher $\mathrm{q}_{1}$ increases $\mathrm{R}_{1}$ (but lowers $\mathrm{R}$ ), since $\mathrm{p}$ is reduced thus incentivizing higher policy bloc fuel demand. Indeed, this is the basic purpose for the policy bloc of "subsidizing offsets" in the fringe.

\subsection{The policy bloc solution}

An authority representing the entire policy bloc sets $t_{1}$ and $q_{1}$ to maximize $W_{1}$ in (1), considering its own fuel demand response (15), the aggregate fuel demand response (13), and the export price response (14), to changes in $t_{1}$ and $q_{1}$; while the exporter tax, $s_{1}$, is taken as exogenous. The solution concept is (static) non-cooperative Nash Equilibrium (NE) where the policy bloc sets carbon tax and offset price, and the exporter bloc sets a fuel export tax; each taking the other's strategy variable(s) as exogenous.

Appendix 1 now shows the following result.

Proposition 1: The static NE solution in $t_{1}$ and $q_{1}$ for the policy bloc is given by the following solutions, expressed as functions of $s_{1}$ :

$$
\begin{gathered}
t_{1}=\frac{2 h \gamma}{2(\gamma+\phi)^{2}-h(1+h) \phi^{2}}\left[\phi\left(1-p_{0}-s_{1}\right)+(\gamma+\phi) c\right] \\
q_{1}=\frac{h \gamma}{2(\gamma+\phi)^{2}-h(1+h) \phi^{2}}\left[\phi\left(1-p_{0}-s_{1}\right)+(\gamma+\phi) c\right]=\frac{1}{2} t_{1} .
\end{gathered}
$$

$\mathrm{q}_{1}<\mathrm{t}_{1}$ is here a general result. More specifically, our ratio of one-to-two follows from the linearquadratic structure of the model and is not general. When $h$ is small, $t_{1}$ and $q_{1}$ are both small: the policy bloc then neither charges high domestic carbon taxes nor induces much offsets in the fringe, for two separate reasons. First, with low h, the climate externality for the policy bloc, hc, 
and the related "Pigou" tax, is small. Secondly, market power of the policy bloc in the fossil fuel market is then small.

The reason why the offset incentive price, $\mathrm{q}_{1}$, is lower than the domestic carbon tax $\mathrm{t}_{1}$ in the policy bloc, is that offset payments go to foreigners, which reduces the attractiveness of foreign offsets, relative to domestic mitigation via the carbon tax $t_{1}$. The policy bloc acts as a monopsonistic purchaser of offsets from fringe countries (which act non-cooperatively), and limits its offset purchases to maximize its net return from such purchases.

When the offset price instead is exogenous (and not necessarily optimal), we have

$$
t_{1}=\frac{h}{(\gamma+\phi)^{2}-h^{2} \phi^{2}}\left[\gamma(\gamma+\phi) c+\gamma \phi\left(1-p_{0}-s_{1}\right)+(1-h) \phi^{2} q_{1}\right]
$$

When $\mathrm{q}_{1}$ is higher (corresponding to a larger volume of offsets), $\mathrm{t}_{1}$ is set higher in response. Intuitively, more offsets in the fringe leads to a lower fuel export price which makes a higher carbon tax in the policy bloc advantageous.

\subsection{The exporter solution}

The exporter bloc maximizes bloc welfare, $\mathrm{W}_{2}$, with respect to its fuel export tax $\mathrm{s}_{1}$, given the supply function (12) from its individual producers, and the price relation (14). Still invoking the NE concept, $\mathrm{t}_{1}$ and $\mathrm{q}_{1}$ are taken as given by the exporter.

I now solve for $\mathrm{s}_{1}, \mathrm{p}$ and $\mathrm{R}$, as functions of the carbon tax $\mathrm{t}_{1}$ and offset subsidy rate $\mathrm{q}_{1}$ set by the policy bloc. The following result emerges, shown in Appendix A.

Proposition 2: The static NE solution for $s_{1}$ is the following function of $t_{1}$ and $q_{1}$ :

$$
s_{1}=\frac{\gamma}{2 \gamma+\phi}\left(1-p_{0}-h t_{1}-(1-h) q_{1}\right)+\frac{\gamma+\phi}{2 \gamma+\phi} c_{2} .
$$


As expected, $s_{1}$ is reduced in response to increased $t_{1}$ and $q_{1}$. This effect is stronger for $t_{1}\left(q_{1}\right)$ when $h>(<) \frac{1}{2}$, so that the fraction of the policy bloc in total fuel demand is greater (smaller) than one half. Interestingly, when offsets are used $\left(q_{1}>0\right)$, the exporter's fuel tax is lower.

\subsection{Overall Nash Equilibrium}

Simultaneously solving (17), (18) and (20) for $t_{1}, q_{1}$ and $s_{1}$ gives the following result.

Proposition 3: The simultaneous, static, NE for the non-cooperative tax-setting game between the policy bloc and the fuel exporting bloc is characterized by

$$
\begin{gathered}
t_{1}=\frac{2 h \gamma}{D_{1}}\left[\phi\left(1-p_{0}-c_{2}\right)+(2 \gamma+\phi) c\right]=2 q_{1} \\
s_{1}=\frac{1}{D_{1}}\left\{[2 \gamma(\gamma+\phi)-h(1+h) \gamma \phi]\left(1-p_{0}\right)+\left[2(\gamma+\phi)^{2}-h(1+h) \phi^{2}\right] c_{2}-h(1+h) \gamma^{2} c\right\},
\end{gathered}
$$

where

$$
D_{1}=(\gamma+\phi)[2(2 \gamma+\phi)-h(1+h) \phi] \text {. }
$$

To interpret these expressions we rely on simulations based on simplifying parametric assumptions; and comparative-static results; all presented in section 4.

Two further features are considered. First, the “incentivized emissions” level describes net emissions as an outcome of incentive mechanisms applied ( $\mathrm{t}_{1}$, and $\left.\mathrm{q}_{1}\right)$, both in the policy bloc and in the fringe. This emission level corresponds notionally to a cap discussed under model 2 in the next section. It can be defined by

$$
R_{I 1}=R_{1}-\Delta R_{F}=\frac{1}{\gamma}\left[h(1-p)-\frac{1}{2}(1+h) t_{1}\right]
$$


This magnitude is simulated in section 4 , in some parametric cases. In all cases studied, $\mathrm{R}_{\mathrm{I} 1}>0$ (optimal emissions in the policy bloc always exceed emissions offset by the fringe).

The second feature is abatement in the policy bloc versus fringe (in terms of reducing $\mathrm{R}$ ), via the tax and offset policies applied. From (13) (noting that $t_{1}=2 q_{1}$ ), $R$ is reduced more (less) in the policy bloc than in the fringe given that $h>(<) 1 / 3$. Thus in particular, when $h=1 / 3$ it is optimal for the policy bloc to implement equally much abatement in each of the two blocs.

\section{Model 2: The Policy Bloc Uses Cap-and-Trade}

\subsection{Basics}

In the second model, the policy bloc sets a cap on its emissions, still taking fringe demand as exogenous. This cap can be achieved in part through offsets purchased from the fringe by the policy bloc, which give room for higher emissions within the policy bloc for a given cap. Call the cap $R_{P}$, and the amount of offsets $R_{F P}$. Emissions by the policy bloc, $R_{1}$, are then given by $R_{P}$ $+R_{F P}$ (offsets allow for policy-bloc emissions above the cap). Denote fringe emissions by $R_{F}$, and fringe emissions in the (counterfactual, but here still well defined) case with no offsets by $R_{F 0}$; then $R_{F}=R_{F 0}-R_{F P}$. Total emissions, $R$, are given alternatively as $R_{1}+R_{F}$, or $R_{P}+R_{F 0}$. $I$ assume free trading of emissions rights within the policy bloc at a single quota price $t_{2}$ (applying parallel symbols with the tax case). As a condition for offset market equilibrium in the quota market, emission offsets need to be purchased from the fringe at price $t_{2}$ : domestic emitters in the policy bloc must be indifferent between abating one unit of emissions, and purchasing one unit of offsets whereby abatement is avoided.

The equilibrium concept is simultaneous NE where the policy bloc determines the quantity of fuel demand and the exporter sets the fuel export tax. In calculating its optimal fuel demand 
(including any offsets), the policy bloc takes the export tax as given, as in model 1 . The main difference from model 1 is that the exporter, in setting its optimal export tax, takes net fuel demand by the policy bloc (incorporating any demand reduction induced in the fringe by the offset policy), and not the carbon price, as given.

I put two constraints on the number of allowable offsets, $R_{F P}$. First, $R_{F P}$ must be non-negative. Secondly, $\mathrm{R}_{\mathrm{FP}}$ cannot exceed abatement in the fringe, given a uniform carbon price $\mathrm{t}_{2}$ enforced in the fringe. A carbon price no greater than $\mathrm{t}_{2}$ would then implement the offset quota $\mathrm{R}_{\mathrm{F} 0}$. As under model 1, I assume efficient offsets: for emissions that are offset through incentive payments from the policy bloc to the fringe, the mitigation cost is lower than for any one unit of residual emissions (where offsets are not taking place). ${ }^{7}$ We can treat the strategy of the policy bloc as setting the quota trading price of emission rights (or tax) within the bloc, which is dual to the quantity solution. The basic strategy of the fringe is also the same in this case as under policy.

A consequence is that the amount of offsets in the fringe, to be financed by the policy bloc, is still given by (8). The offset price is however different here. Use of c-a-t (and with no "quota discounts" for offsets as discussed in the final section) requires the offset price in the fringe to equal the domestic quota price in the policy bloc countries (equivalent to the $\operatorname{tax}_{2}$ ) as a condition for market clearing in the quota market. In the last expression in (1), $\mathrm{q}_{2}$ is then replaced by the domestic trading price in the policy bloc, $\mathrm{t}_{2}$. No similar constraint on the offset trading price was imposed in model 1 , where the policy bloc implemented offsets directly via transfer payments to fringe countries, and the offset trading price could be set freely.

\subsection{Importer solution}

\footnotetext{
${ }^{7}$ This is not an obvious outcome, since the unit incentive pay by policy bloc emitters to the fringe, $\mathrm{t}_{2}$, is generally higher than the carbon price that would otherwise implement the actual offsets taking place in the fringe.
} 
(10)-(16) from model 1 are still valid. The fuel demand functions of the policy bloc and the fringe, as viewed by each, are still given by (3) and (6), where t in (3) is interpreted as the quota price within the c-a-t scheme in the policy bloc. Policy-bloc fuel demanders (and emitters) still maximize profits given the fuel price including the quota price, serving as a "tax" within the policy bloc. The strategy of the policy bloc itself can also be viewed as very similar to model 1 . This is because the tax and c-a-t solutions are formally identical for fuel consuming countries facing a given fuel import price, under full certainty and with full auctioning of emissions quotas. (15) can be interpreted, alternatively, as the condition for optimal energy demand $\mathrm{R}_{1}$, or for optimal quota price t, in either case taking the fuel import price, p, from (12), and $s$ as exogenous.

Proposition 4: When the importer bloc uses a c-a-t policy with optimal offsets and assuming free offset trading, the constrained optimal quota price, $t_{2}$, expressed in terms of the exporter tax, $s_{2}$, equals the offset price and is given by

$$
t_{2}=\frac{h^{2} \gamma}{(\gamma+\phi)^{2}-h^{2} \phi^{2}}\left\{\phi\left(1-p_{0}-s_{2}\right)+(\gamma+\phi) c\right\}=q_{2} .
$$

Moreover, the solution entails

$$
p+t_{2}=m
$$

where $m$ is the marginal productivity of energy use in both the policy bloc and the fringe.

Proof: See the appendix.

The appendix demonstrates that the constrained optimal solution for the importer takes the form of a corner solution where a maximum number of offsets is utilized for the given offset price, 
which equals the carbon trading price within the c-a-t scheme in the policy bloc. This result has a simple intuitive explanation: For a given cap (which effectively constrains energy consumption within the policy bloc) and given that offsets and quotas are sold at the same price, the policy bloc wishes to consume as much fossil energy as possible which means that it uses offsets to the maximum extent (for given offset price). This is different from Section 2, where the offset price was independently optimized, and set lower than that tax. The offset amount was then also lower for any given (policy bloc-internal) carbon price.

Comparing (24) to (17), $t_{2}<t_{1}$ (for any given export tax s); but the difference is small when $h$ is close to one. When $\mathrm{h}$ is low, by contrast, the difference is greater; and $\mathrm{t}_{2} / \mathrm{t}_{1}$ tends to zero as $\mathrm{h}$ goes to zero.

All net offset market rent is here captured by fringe emitters. This follows from the assumption of perfect competition and free arbitrage in the offset market, so that all units in that market (whether domestic in the policy bloc or purchased from the fringe) need to be traded at a uniform price.

Offsets are in general more costly to the policy bloc in this case than under model 1 (where they could be bought at a "discount" relative to the domestic carbon tax $t_{1}$ ); here they must be paid at full cost $t_{2}$. But this also serves to reduce the internal carbon price within the policy bloc, $t_{2}$, below $\mathrm{t}_{1}$ in model 1.

\subsection{Exporter solution}

For fuel exporters, c-a-t is more dramatically different from a carbon tax solution for the policy bloc. Exporters no longer face an importer tax, but instead a cap by the policy bloc, in amount $\mathrm{R}_{\mathrm{P}}$. Instead of (9), the exporter faces the aggregate fuel demand function 


$$
R=R_{1}+R_{F}=R_{P}+R_{F 0}=R_{P}+(1-h) \frac{1-p}{\gamma}
$$

$\mathrm{R}_{\mathrm{P}}$, the emissions cap set by the policy bloc, includes possible offsets purchased by the policy bloc from the fringe, so that actual policy bloc emissions may exceed $R_{P}$ by the amount of offsets. The exporter now takes $\mathrm{R}_{\mathrm{P}}$ as fixed, and only the baseline demand by the fringe, $\mathrm{R}_{\mathrm{F} 0}$, as variable. We have the following result, shown in the appendix:

Proposition 5: When the policy bloc chooses a c-a-t solution, the optimal strategy of the exporter bloc is to set its export tax s according to

$$
S_{2}=\frac{\gamma}{(2-h) \gamma+(1-h) \phi}\left(1-p_{0}-h t_{2}-(1-h) q_{2}\right)+\frac{(1-h)(\gamma+\phi)}{(2-h) \gamma+(1-h) \phi} c_{2} .
$$

Comparing (27) to (20), we find $s_{2}>s_{1}$ (from model 1) for any given $t_{2}$ and $q_{2}$. The exporter is (much) more aggressive in setting its export excise tax when the importer chooses a c-a-t policy, than when it chooses a tax policy. The difference is greater when $h$ (the share of the policy bloc among all fuel demanders) is larger. Simulations, discussed in section 4 below, also indicate that $\mathrm{s}_{2}>\mathrm{s}_{1}$ more generally.

The export price, p, can be expressed as

$$
p-p_{0}=\frac{\gamma+(1-h) \phi}{(2-h) \gamma+(1-h) \phi}\left(1-p_{0}-h t_{2}-(1-h) q_{2}\right)+\frac{(1-h) \gamma}{(2-h) \gamma+(1-h) \phi} c_{2}
$$

Comparing to the carbon tax case, $\mathrm{p}$ is greater here for any given $\mathrm{t}$ (where $\mathrm{t}=\mathrm{t}_{1}$ is the carbon tax in model 1 , and $t=t_{2}$ the quota price in model 2). We find: 


$$
\frac{d p}{d h}=\frac{\gamma^{2}}{[\gamma+(1-h)(\gamma+\phi)]^{2}}\left(1-p_{0}-h t_{2}-(1-h) q_{2}-c_{2}\right)-\frac{\gamma+(1-h) \phi}{\gamma+(1-h)(\gamma+\phi)} \frac{d\left(h t_{2}\right)}{d h}
$$

This expression is always positive for given $\mathrm{ht}_{2}$ (so that $\mathrm{t}_{2}$ falls proportionately). But it is also positive when $\mathrm{ht}_{2}$ increases in $\mathrm{h}$, provided that the first term dominates the second. This is always so when $\mathrm{h}$ is initially small; $\mathrm{t}_{2}$ is then also small (from (30) below); and $\mathrm{d}\left(\mathrm{ht} \mathrm{t}_{2}\right)$ must consequently be small. We thus find that when $h$ is small at the outset, the export price always increases when the policy bloc comprises a larger fraction of total fuel demand (h increases). This is diametrically opposite to the conclusion under model 1 , where the policy bloc used a carbon tax. We find, in the simulations in section 4 below, that $\mathrm{p}$ can increase in $\mathrm{h}$, also for larger $\mathrm{h}$ values (when c is low).

It is important to stress that the behavior of the policy bloc is formally identical in the two models (except for the constraint $\mathrm{t}_{2}=\mathrm{q}_{2}$ only in model 2); despite the fact that the policy bloc sets a tax in the first, and a cap in the second model. It occurs because the two problems, maximizing with respect to the cap, and to the tax, yield the same result for given behavior of the exporter. It follows from duality of the tax and cap solutions: both implement the same allocation under competitive conditions. The difference between the two models lies in the response of a non-competitive exporter to the chosen policy bloc strategy, tax or cap.

\subsection{Overall Equilibrium}

Overall equilibrium is found by solving (24) and (27) for $\mathrm{t}_{2}$ and $\mathrm{s}_{2}$ (noting that $\mathrm{q}_{2}=\mathrm{t}_{2}$ ).

Proposition 6: Given that the importer bloc uses a c-a-t policy with free offset trading, and the exporter sets an optimal fuel export tax, the static $N E\left(t_{2}, s_{2}\right)$ combination is given by 


$$
\begin{gathered}
t_{2}=\frac{h^{2} \gamma}{D_{2}}\left\{[(2-h) \gamma+(1-h) \phi] c+(1-h) \phi\left(1-p_{0}-c_{2}\right)\right\} \\
S_{2}=\frac{(1-h)\left[(\gamma+\phi)^{2}-h^{2} \phi^{2}\right] c_{2}+\gamma\left[\gamma+\left(1-h^{2}\right) \phi\right]\left(1-p_{0}\right)-h^{2} \gamma^{2} c}{D_{2}}
\end{gathered}
$$

where

$$
D_{2}=(\gamma+\phi)\left[2 \gamma+\left(1-h^{2}\right) \phi\right]-h\left[(\gamma+\phi)^{2}-h^{2} \phi^{2}\right] .
$$

$t_{2}$ here tends to $\mathrm{c}$ as $\mathrm{h}$ tends to one. $\mathrm{t}_{2}$ is always rising in $\mathrm{h}$ for low $\mathrm{h}$, but could fall or rise for larger h; this is found in comparative static results, and in simulations in section 4 below.

$\mathrm{s}_{2}=\mathrm{s}_{1}$ from model 1 for $\mathrm{h}=0$ and no climate policy. When $\mathrm{h}>0, \mathrm{~s}_{2}>\mathrm{s}_{1}$ and more so when $\mathrm{h}$ is higher. The exporter adopts a more aggressive taxation strategy the higher is $h$, since the fuel demand elasticity faced by the exporter is lower (as less of fuel demand is variable).

Consider implications of the overall solution for the optimal "cap" to be set, analogously to the amount of "incentivized emissions" (from (23)) under model 1. The optimal cap, $\mathrm{R}_{\mathrm{C} 2}$, is

$$
R_{C 2}=R_{1}-\Delta R_{F}=\frac{1}{\gamma}\left[h(1-p)-t_{2}\right] .
$$

Simulations in section 4 show that $\mathrm{R}_{\mathrm{C} 2}>0$ independent of $\mathrm{h}$. This is similar to what was found in model 1. The intuition is also here that for low $\mathrm{h}$ (where, conceivably, the cap could be negative) the emissions price is too low to really matter in terms of emissions reductions.

Compare also here the amounts of abatement taking place in the policy bloc versus in the fringe. From (13), (15) and (16) and inserting $\mathrm{q}_{2}=\mathrm{t}_{2}$ we now simply have 


$$
\begin{gathered}
R_{1}=\frac{h}{2}\left(1-s-t_{2}\right)=h R \\
R_{F}=\frac{1-h}{2}\left(1-s-t_{2}\right)=(1-h) R .
\end{gathered}
$$

Thus in this case fuel demand in the policy bloc and fringe are proportional to bloc size. This is simply a consequence of fuel consumption being efficiently allocated across fuel-consuming countries in this case, from (25). ${ }^{8}$

\section{Comparative Statics with Simulations}

I will now discuss some key comparative-static results given changes in two key exogenous parameters, $\mathrm{h}$ (the share of fuel importers with a climate policy) and c (the global externality of GHG emissions for fuel importers). ${ }^{9}$ These are illustrated by model simulations in a simple numerical example where $\mathrm{p}_{0}=\mathrm{c}_{2}=0$ (the exporter's fuel supply function has intercept at zero, and no negative climate impacts on the exporter), and $\gamma=\varphi=1$ (demand and supply functions for fossil fuels are equally sloped). ${ }^{10}$ In figures 1-8, all model 1 variables are in blue (except $\mathrm{q}_{1}$ which is in green), and all model 2 variables are in red. Figures 1-3 illustrate solutions as functions of $\mathrm{h}$ (the fraction of the fuel demand market represented by the policy bloc), for three alternative values of c: = 0 (no climate concern); =1/4 (“medium" climate concern); and =1/2 (“high” climate concern). Five variables are shown in figures 1-3: clockwise from upper left t and q (the carbon tax and offset price); s (the exporter fuel tax); p (fuel export price); and R

\footnotetext{
${ }^{8}$ This is an idealized model where the offset markets are assumed to function perfectly; in particular, all units of excess emissions in the fringe are perfectly offset using the offset price $t_{2}$. This is clearly not realistic; see the discussion of this issue in the conclusion below.

${ }^{9}$ I thank Sauleh Siddiqui for invaluable help in creating the simulations and figures.

${ }^{10}$ The exact comparative-static results are not reproduced; they can be obtained from the author upon request.
} 
(consumed amount of the resource); all as functions of $\mathrm{h}$ (the policy bloc as share of fueldemanding countries).

When $c=0$ (figure 1 ), everything is driven by strategic concerns. As noted, $q_{1}=1 / 2 t_{1}$. Both are higher than $\mathrm{q}_{2}\left(=\mathrm{t}_{2}\right)$. While $\mathrm{t}_{1}$ and $\mathrm{q}_{2}\left(=\mathrm{t}_{2}\right)$ differ also for small $\mathrm{h}$, the difference is greater for larger h. ${ }^{11}$ The carbon price of the policy bloc is dramatically higher under a carbon tax than under c-a-t when $\mathrm{h}$ is high. While the carbon tax increases strongly in $\mathrm{h}$, the quota price in the c$\mathrm{a}-\mathrm{t}$ case also increases in $\mathrm{h}$ up to a certain point, but is reduced when $\mathrm{h}$ increases further. Two factors give opposite effects on $\mathrm{t}_{2}$ : a higher $\mathrm{h}$ makes the policy bloc more collusive and more aggressive in its pricing; but a higher $\mathrm{h}$ also makes the exporter (much) more aggressive which reduces the scope for rent extraction by the policy bloc. Interestingly, the policy bloc's carbon price is always positive even as there is no climate concern in this case.

----- Figure 1 in about here -----

Fossil fuel consumption drops in h, only slightly in the tax case, and more dramatically in the cap case, as the exporter price then increases drastically. The tax case is "good" for importers as the import price is substantially reduced when $\mathrm{h}$ increases.

Figures 2 and 3 (“intermediate” and "high" climate concern) differ more from figure 1 as $\mathrm{h}$ grows. This is because a climate concern of the policy bloc affects policy very little when $\mathrm{h}$ is small, but much more when $\mathrm{h}$ is high: the carbon tax and quota price are then also much higher. In particular, the quota price under c-a-t rises uniformly in $h . \mathrm{q}_{2}$ now (slightly) exceeds $\mathrm{q}_{1}$ for high $h$ (greater than about 0.65 for $c=1 / 4$; and greater than about 0.6 for $c=1 / 2$ ). This more

\footnotetext{
${ }^{11}$ As noted, however, the model is less suitable for describing what happens under a cap solution for high h values.
} 
aggressive carbon pricing strategy of the policy bloc leads to a greater reduction in both the import price, and total fossil fuel consumption, when h increases.

----- Figures 2 and 3 in about here -----

Generally, $t_{1}>t_{2}$ for all values of $h$ and $c$. This difference is however not uniformly greater when $\mathrm{h}$ is higher. Two main factors explain this. First, $\mathrm{s}_{2}>\mathrm{s}_{1}$ always, and the difference is greater when $h$ is higher. The importer's optimal response is to set $t_{1}>t_{2}$ (when the exporter tax, and thus the export price, is lower). ${ }^{12}$ The second factor is related to the functioning of the offset market. In the tax case, under model 1, the domestic carbon tax in the policy bloc is independent of the offset price (effective within the fringe); there is no direct effect of the offset market on the domestic carbon tax. In model 2, by contrast, the offset carbon price must equal the carbon price within the policy bloc. This puts downward pressure on the carbon price when the policy bloc is small and the fringe is large (h small), and the offset market is a large share of total abatement. When the fringe is small (h large), by contrast, this factor is less important (as the offset market is also less important). There is then less downward pressure on the carbon price from an offset market under the cap.

These two factors work in opposite directions with respect to $\Delta t=t_{1}-t_{2}$ when $h$ increases. When $\mathrm{c}=0, \Delta \mathrm{t}$ increases strongly in $\mathrm{h}$. When $\mathrm{c}=1 / 4, \Delta \mathrm{t}$ increases but more slowly over a large range for h. When $\mathrm{c}=1 / 2, \Delta \mathrm{t}$ is reduced for higher $\mathrm{h}$.

\footnotetext{
${ }^{12}$ In the limit as h tends to unity, under a cap the NE solution in this model entails the exporter setting the export price at its maximal level choking off demand. The carbon quota price is then equal to zero. This is an unrealistic economic model; see Strand (2010) for elaboration and discussion of alternative equilibrium concepts.
} 
As noted, $\mathrm{t}_{1}=2 \mathrm{q}_{1}$, while $\mathrm{t}_{2}=\mathrm{q}_{2}$. Still, $\mathrm{q}_{2}<\mathrm{q}_{1}$ for low $\mathrm{h}$ and/or low c; but $\mathrm{q}_{2}>\mathrm{q}_{1}$ when both $\mathrm{h}$ and c are high. When $\mathrm{h}$ is low, the dominating factor is the "drag” (toward low carbon prices) from the constraint $t_{2}=q_{2}$ under c-a-t. When $h$ is high, by contrast, the offset market is small and pricing in that market means little for efficiency within the policy bloc. When c is high (and the quota price high under c-a-t for high $\mathrm{h}$ ), $\mathrm{q}_{2}=\mathrm{t}_{2}$ then implies $\mathrm{q}_{2}>\mathrm{q}_{1}$ in such cases.

The more general comparative-static results show that $t_{1}$ rises, while both $\mathrm{s}_{1}$ and $\mathrm{R}$ in model 1 fall, when both $\mathrm{h}$ and c increase. ${ }^{13}$ The same holds when c changes in model 2 . Effects of $\mathrm{h}$ on $\mathrm{t}_{1}$ and $\mathrm{s}_{2}$ as $\mathrm{h}$ are slightly more complex. When c is small, $\mathrm{dt}_{2} / \mathrm{dh}>0$ always when $\mathrm{h}$ is small; and $\mathrm{dt}_{2} / \mathrm{dh}<0$ always when $\mathrm{h}$ is large. When c is high, $\mathrm{t}_{2}$ rises uniformly in $\mathrm{h} . \mathrm{s}_{2}$ always rises in $\mathrm{h}$ when $\mathrm{c}$ is small, and always falls in $\mathrm{h}$ when $\mathrm{c}$ is high and $\mathrm{h}$ already high. This confirms the main results from the simulations in figures 1-3.

Figure 4 shows "incentivized quotas" $\mathrm{R}_{\mathrm{I}}$ in (23), and $\mathrm{R}_{\mathrm{C} 2}$ in (32) for the simulated example. Under my numerical example these two expressions are found as

$$
\begin{gathered}
R_{I 1}=\frac{h}{2}\left[1-s_{1}-\frac{1}{2}(3-h) t_{1}\right] \\
R_{C 2}=h\left(1-s_{2}-R\right)-t_{2} .
\end{gathered}
$$

$\mathrm{R}_{\mathrm{C} 2}$ corresponds to the optimal quota (accounting for offsets) set by the policy bloc in model 2. $\mathrm{R}_{\mathrm{I} 1}$ has a similar interpretation in model 1 (except that a government-managed offset scheme is here assumed instead of a free offset trading scheme). “Optimal quotas” are similar in the two models for low h (slightly greater in model 2); but are much smaller in model 2 for high h.

\footnotetext{
${ }^{13}$ Analytical results can be obtained from the author upon request.
} 
Figures 5-7 show welfare levels for the policy bloc, fringe and exporter bloc under models 1-2. Most strikingly, for both policy bloc and fringe, utility is everywhere higher in model 1 than in model 2. As is easily verified, this result holds generally and does not rely on the chosen parameter values. For the policy bloc, the difference in outcome under the two models grows with $h$, as seen from the figures. In a relevant example, $h=1 / 4$ (as for Annex B under the Kyoto Protocol), the difference in utility for the policy bloc is small, and it matters little to the policy bloc whether a tax or a c-a-t solution is chosen. When the policy bloc is larger, the difference can be large, and the choice of policy regime a major concern for the policy bloc. ${ }^{14}$ Exporter welfare is greater with c-a-t then with carbon taxes, for $\mathrm{h}$ values up to a maximum point. For even higher $\mathrm{h}$ values, the aggression in exporter fuel price setting (as fuel demand becomes less elastic) backfires, as fuel output tends to zero when $\mathrm{h}$ tends to one.

----- Figures 5-7 in about here -----

We finally simulate net welfare of fringe countries due to offsets (disregarding climate effects), expressed by $\mathrm{B}_{\mathrm{F}}$, which takes the form

$$
B_{F}=\frac{1-h}{2} q^{2},
$$

where $\mathrm{q}$ is the generic offset price, given by $\mathrm{t}_{1} / 2$ from (21) under model 1 , and by $\mathrm{t}_{2}$ from (30) under model 2. Simulations for three alternative values of $\mathrm{c}(=0,1 / 4$, and $1 / 2)$ are shown in figure 8. For moderate values of $h(<0.6)$ the welfare gain to the fringe from an offset market is

\footnotetext{
${ }^{14}$ For such c values or higher, utilities tend to be negative in the model, for both fuel-consuming blocs. This is due to the large negative externalities from emissions. It would then have been better to have no fossil fuels available at all. This is not realistic, but follows from my assumption that the choke price of fossil fuels is quite low (= 1 and thus only twice the externality value for $\mathrm{c}=0.5$ ), and the demand function linear.
} 
everywhere greater under a tax than under c-a-t. This mirrors results for q from figures 1-3: wherever $\mathrm{q}_{1}>(<) \mathrm{q}_{2}$ welfare gains from offsets are greater (smaller) under model 1 .

----- Figure 8 in about here -----

\section{Conclusions and Final Comments}

This paper has analyzed a carbon tax versus an emissions cap with free quota trading (c-a-t) as alternative climate policy strategies for a fossil fuel-importing "climate policy bloc" facing a fuel-importing group of countries (a "fringe"), with no climate policy, and a fuel-exporting bloc which sets its fuel export tax optimally. The optimal carbon price in the policy bloc is influenced by both a climate ("Pigouvian") motive, and a strategic motive whereby the policy bloc influences the exporter's fuel price through its tax or cap. A positive carbon tax leads to a lower fuel import price, which benefits all fuel importers including the fringe. The tax is set higher when the policy bloc is larger, for two reasons: the "Pigou" element is then greater; and the strategic element, whereby the tax reduces overall fuel demand and the fuel export price, is greater.

I find that a carbon tax is always preferred over a c-a-t policy by fuel importers, mainly because fuel exporters charge a lower fuel price under a carbon tax than under c-a-t. Under c-a-t, once a cap has been set, overall fuel demand is less sensitive to the fuel export price than under a carbon tax. This gives a monopolistic exporter an incentive to set its export price higher under c-a-t than under a carbon tax, and this hurts all importers. Having an offset market is also more advantageous to the policy bloc under a carbon tax in my model, because the offset price can be set lower than the tax, while unified trading makes price differentiation between domestic quotas and offsets infeasible under c-a-t. The fringe also fares better under a carbon tax, and more so 
when the policy bloc is larger and the fringe smaller. A small fringe benefits more from being a "free rider" on a (relatively high) carbon tax set by the larger policy bloc, which pushes the fuel export price down.

To my knowledge this paper represents the first attempt in the literature to analyze optimal offset policies in the context of a global model of strategic GHG mitigation policy. Being a first attempt, the analysis is stylized. Offset markets are assumed to be fully efficient, with the "best" projects always implemented, and all offsets additional. My assumption that when the fringe faces an offset price equal to q, the mitigation in the fringe is the same as it would be when facing this level of carbon tax, is not realistic. Several problems with the CDM have been uncovered, including lack of additionality (many projects would have been implemented even without CDM financing; see Hagem (1996), Fischer (2005); Flues, Michaelowa and Michaelowa (2010)), manipulation of baselines (Wirl, Huber and Walker (1998), Fischer (2005), Strand and Rosendahl (2012)), and leakage (Rosendahl and Strand (2011)); which all limit the global abatement effects of CDM projects.

Offset markets are assumed to be designed differently in the two cases. In the carbon tax case offsets are purchased directly by a central authority, with a single offset price that may differ from the carbon tax. In the c-a-t case, by contrast, the offset mechanism is market-based and of a standard CDM type. In my view these are logical ways of organizing an offset market in the two cases; but they are not the only ways. In one sense, my model can be seen as "stacked against" the c-a-t solution and in favor of the tax solution by allowing the policy bloc to price discriminate in the offset market only in the tax case. One might alternatively consider ways in which to differentiate the "domestic" and "foreign" markets under c-a-t, allowing for different prices in the two sub-markets also with private trading. Some authors, including Castro and 
Michaelowa (2010), and Klemick (2012), have discussed offset “discounts” (the purchaser of an offset can increase its emissions by only a fraction of the purchase), which might be preferable when offsets are not fully additional. Bargaining over net returns from individual CDM projects might also be relevant. With project bargaining, market arbitrage will no longer hold for offset quotas, which will be priced lower, as discussed by Bréchet, Ménière and Picard (2011) who stress that a greater bargaining power to project sponsors makes offsets more attractive for the policy bloc. One may also question whether a totally separate sub-market for offsets (managed e g by governments) can provide the same degree of efficiency as an integrated, private, domestic and foreign c-a-t market. The wider implications of alternative offset market mechanisms should remain as a priority topic for future research, given that non-policy countries continue to play important roles for global GHG mitigation. In realistic cases, offsets might then be found to represent a less attractive option for a policy bloc, so that their optimal volume is smaller. However, given a large fringe, offsets might still play a significant role.

Considering the overwhelming evidence in favor of tax over cap solutions, in this and most other modeling contexts, a natural question is, why are c-a-t solutions at all used? I will not enter a deep discussion, only note that in various policy contexts there are strong biases against solutions that put a direct price (or tax) on energy resources, and in favor of more roundabout and indirect, and less efficient, solutions. Heavy political economy issues often seem to lie behind: in the U.S. and many other countries, biases against taxes in general; in the EU, succumbing to political pressure from industry lobbies to spare energy-intensive sectors from any burden of the EU-ETS (demanding c-a-t systems with high levels of free allocations); and in many other countries strong populist pressure not to tax (but often rather subsidize) fuels and electricity. Hopefully, this analysis can serve as an additional reminder that energy tax solutions can be highly 
beneficial, and where one key additional argument (relative to standard ones) is offered, namely the effects on fuel price setting and thus terms of trade which, independently of other factors, make tax solutions unambiguously favorable for fuel importers.

My model is highly simplified and could be changed or expanded in other ways than those already discussed. I here only briefly mention a few possibilities.

A) Static analysis, while fossil energy extraction and climate change are both inherently dynamic processes. A key question is whether main results, such as preference of a tax over a cap in climate policy for fuel importers, carries over to a dynamic context. Some ongoing research indicates that they do. Wirl (2012) has recently shown that taxes are chosen over caps in a corresponding dynamic model of two monolithic blocs but no fringe. ${ }^{15}$ Work is also in progress on the (analytically more intriguing) dynamic case with a fuel importing fringe. See Karp, Siddiqui and Strand (2013), with results pointing in the same direction. ${ }^{16}$

B) No fuel production in consuming countries, and no fuel consumption in fuel-producing countries. Changing this would eliminate some extreme cases (including non-existence of positive resource extraction under c-a-t for $\mathrm{h}=1$ ), but would otherwise leave main results intact.

C) Only one fuel. Strand (2011) considers two differentiated fuels in a model of two blocs only (exporters and importers). This changes conclusions slightly, by making the ex post fuel demand function more elastic under c-a-t. While this increases the attractiveness of the c-a-t solution, the basic preference for taxes still remains.

\footnotetext{
${ }^{15}$ Wirl (2012) shows that taxes are dominant dynamic instruments also for exporters, as we have assumed here.

${ }^{16}$ The examples simulated in this paper show that the exporter always chooses a tax; and that the policy bloc in response chooses a tax for at least a long initial period (50-100 years). Note that neither Wirl (2012) nor Karp, Siddiqui and Strand (2013) include offset markets. A related, much earlier unpublished paper is Karp (1988).
} 
D) A monopolistic fuel exporter dictates the fuel export price; and there is no fringe of competitive fuel suppliers. Starts of analysis incorporating competitive fringe fuel supply are found in Keutiben (2010), and Karp, Siddiqui and Strand (2013).

E) All fuel-importing regions are equally averse to climate change; and have equal utility loss (relative to population size) per unit of carbon emissions. With different loss parameters, countries' incentives to join the policy bloc will generally vary among countries. The climate impact factor for the policy bloc, here hc, will then also be a more complex function of $\mathrm{h}$.

F) Climate costs are linear in total emissions. More plausibly, climate costs are strictly convex in emissions. With a quadratic cost function we would get an additional quadratic term in (1), reducing the optimal $t_{1}$ and $t_{2}$; and more so the larger is the policy bloc (and $h$ ). In other respects, however, little would change. Also, since climate is a slow-moving variable, convexity is likely not to have a serious impact on policy when considering only relatively short periods (such as a year). In dynamic long-run models (Wirl (2012) and Karp, Siddiqui and Strand (2013)) convexity plays a larger role, making policy more restrictive over time. 


\section{References}

Berg, Elin, Kverndokk, Snorre, and Rosendahl, Knut Einar (1997), Market Power, International CO2 Taxation, and Oil Wealth. The Energy Journal, 18, no 4.

Berger, Kjell, Fimreite, Øyvind, Golombek, Rolf and Hoel, Michael (1992), The Oil Market and International Agreements on CO2 Emissions. Resources and Energy, 14, 315-336.

Bergstrom, Theodore C. (1982), On Capturing Oil Rent with a National Excise Tax. American Economic Review, 72, 194-201.

Bréchet, Thierry, Ménière, Yann and Picard, Pierre (2011), The Clean Development Mechanism in a Globalilzed Carbon Market. Working Paper, CERNA/CORE.

Castro, P. and Michaelowa, Axel (2010), The Impact of Discounting Emission Credits on the Competitiveness of Different CDM Host Countries. Journal of Ecological Economics, 70, 34-42.

Fischer, Carolyn (2005), Project-based Mechanisms for Emissions Reductions: Balancing Tradeoffs with Baselines. Energy Policy, 33, 1807-1823.

Flues, Florens, Michaelowa, Axel and Michaelowa, Kathrina (2010), What Determines UN Approval of Greenhouse Gas Emission Reduction Projects in Developing Countries? An Analysis of Decision Making of the CDM Executive Board. Public Choice, 145, 1-24.

Hagem, Cathrine (1996) Joint Implementation under Asymmetric Information and Strategic Behavior. Environmental and Resource Economics, 8, 431-447.

Hoel, Michael (2010), Is There a Green Paradox? CESifo working papers no 3168.

Hoel, Michael and Karp, Larry (2001), Taxes and Quotas for a Stock Pollutant with Multiplicative Uncertainty. Journal of Public Economics, 82, 91-114.

Hoel, Michael and Karp, Larry (2002), Taxes versus Quotas for a Stock Pollutant. Resource and Energy Economics, 24, 367-384.

Johansson, Daniel J. A., Azar, Christian, Lindgren, Kristian, and Persson, Tobias A. (2009), OPEC Strategies and Oil Rent in a Climate Conscious World. The Energy Journal, 30 no 3, 2350 .

Karp, Larry (1984), Optimality and Consistency in a Differential Game with Non-Renewable Resources. Journal of Economic Dynamics and Control, 8, 73-97.

Karp, Larry (1988), A Comparison of Tariffs and Quotas in a Strategic Setting. Working Paper, University of California, Berkeley. 
Karp, Larry and Costello, Christopher (2004), Dynamic Taxes and Quotas with Learning. Journal of Economic Dynamics and Control, 28, 1661-1680.

Karp, Larry and Newbery, David M. (1991a), OPEC and the U.S. Oil Import Tariffs. The Economic Journal (supplement), 101, 303-313.

Karp, Larry and Newbery, David M. (1991b), Optimal Tariffs on Exhaustible Resources. Journal of International Economics, 30, 285-299.

Karp, Larry, Siddiqui, Sauleh and Strand, Jon (2013), Climate Policy with Dynamic Fossil Fuel Markets: Prices versus Cap-and-Trade. Unpublished, World Bank.

Karp, Larry, and Zhang, Jiangfeng (2010), Taxes versus Quantities for a Stock Pollutant with Endogenous Abatement Costs and Asymmetric Information. Economic Theory, forthcoming.

Keutiben, Octave (2010), On Capturing Foreign Oil Rents. Working Paper, Université de Montréal.

Klemick, Heather (2012), What is the Optimal Offsets Discount under Second-Best Cap-andTrade Policy? National Center for Environmental Economics Working Paper 12-04. Washington DC: Environmental Protection Agency.

Liski, Matti and Tahvonen, Olli (2004), Can Carbon Tax Eat OPEC's Rents? Journal of Environmental Economics and Management, 47, 1-12.

Newbery, David M. (2005), Why Tax Energy? Towards a More Rational Policy. The Energy Journal, 26, 1-40.

Pizer, William A. (2002), Combining Price and Quantity Controls to Mitigate Global Climate Change. Journal of Public Economics, 85, 409-34.

Ploeg, Frederick v.d. and Withagen, Cees (2013), Is There Really a Green Paradox? Journal of Environmental Economics and Management, forthcoming.

Rosendahl, Knut Einar and Strand, Jon (2011), Carbon Leakage from the Clean Development Mechanism. The Energy Journal, 32 no 4, 27-50.

Rubio, Santiago J. (2005), Tariff Agreements and Non-Renewable Resource International Monopolies: Prices Versus Quantities. Discussion paper no 2005-10, Department of Economic Analysis, University of Valencia.

Rubio, Santiago J. and Escriche, Luisa (2001), Strategic Pigouvian Taxation, Stock Externalities and Polluting Non-Renewable Resources. Journal of Public Economics, 79, 297-313.

Salo, Seppo and Tahvonen, Olli (2001), Oligopoly Equilibrium in Nonrenewable Resource Markets. Journal of Economic Dynamics and Control, 25, 671-702. 
Sinn, Hans-Werner (2008), Public Policies Against Global Warming. International Tax and Public Finance, 15, 360-394.

Strand, Jon (2007), Technology Treaties and Fossil-Fuels Extraction. The Energy Journal, 28 no 4, 169-181.

Strand, Jon (2010), Taxes Versus Cap-and-Trade in Climate Policy When Only Some Fuel Importers Abate. CESifo Working Paper no 3233. Munich: CESifo.

Strand, Jon (2011), Taxes and Caps as Climate Policy Instruments With Domestic and Imported Fuels. In Gilbert Metcalf (ed.): U.S. Energy Tax Policy. Cambridge University Press, 2011.

Strand, Jon and Rosendahl, Knut Einar (2012), Global Emissions Effects of CDM Projects with Endogenous Project Baselines. Resource and Energy Economics, 34, 533-548.

Weitzman, Martin L. (1974), Prices Versus Quantities. Review of Economic Studies, 41, no 4, 477-491.

Wirl, Franz (1994), Pigouvian Taxation of Energy for Stock and Flow Externalities and Strategic, Non-competitive Pricing. Journal of Environmental Economics and Management, 26, $1-18$.

Wirl, Franz (2012), Global Warming: Prices Versus Quantities from a Strategic Point of View. Journal of Environmental Economics and Management, 64, 217-229.

Wirl, Franz, Huber, Claus and Walker I. O. (1998), Joint Implementation: Strategic Reactions and Possible Remedies. Environmental and Resource Economics, 12, 203-224. 


\section{Simulations: Figures 1-8}

Figure 1: Carbon prices, export tax, import price and fuel demand, as functions of $h$ for $c=0$

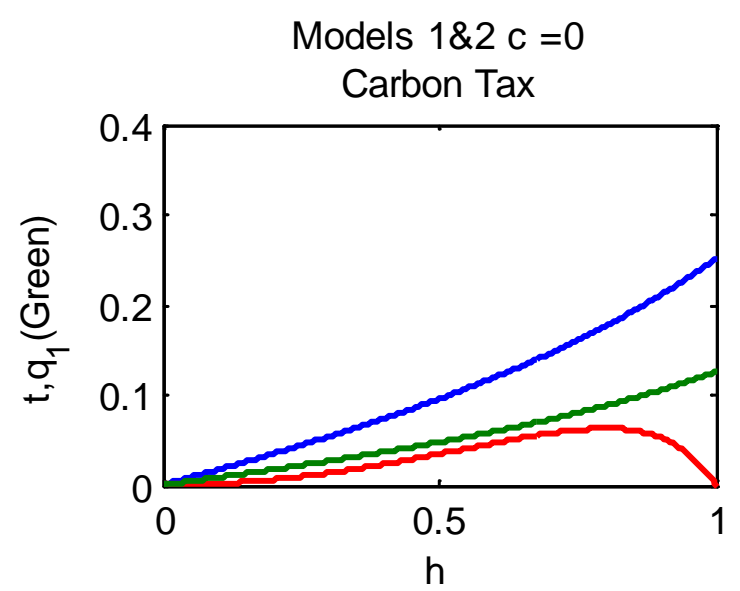

Models $1 \& 2 \mathrm{c}=0$

Aggregate Demand

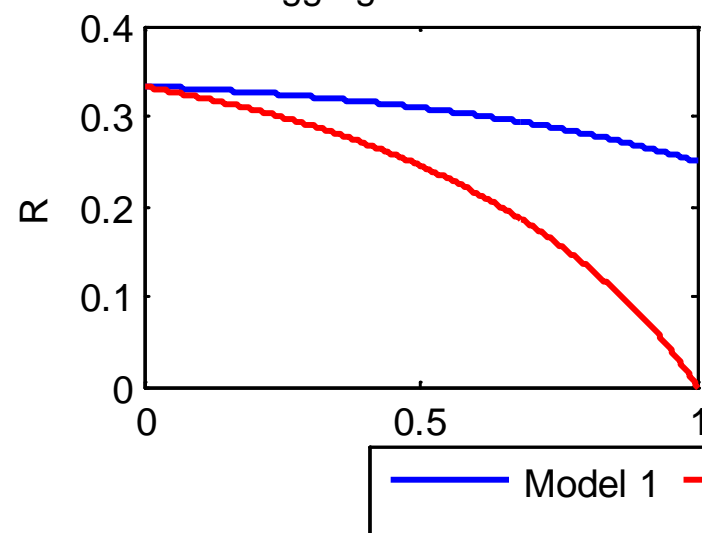

Models $1 \& 2 \mathrm{c}=0$

Export Tax

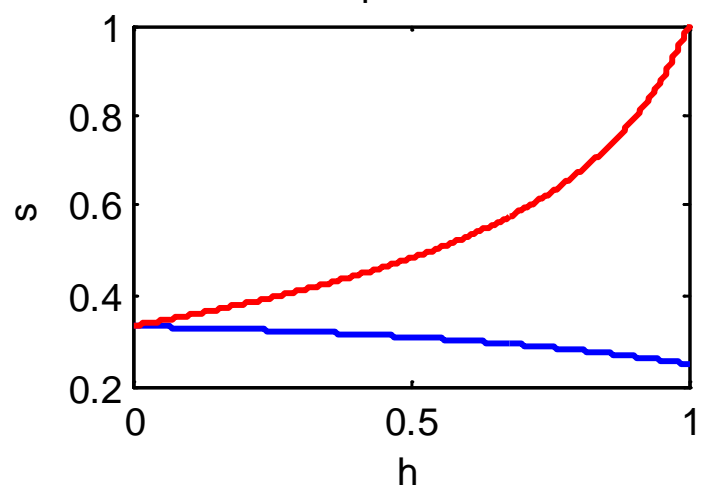

Models $1 \& 2 \mathrm{c}=0$ Import Price

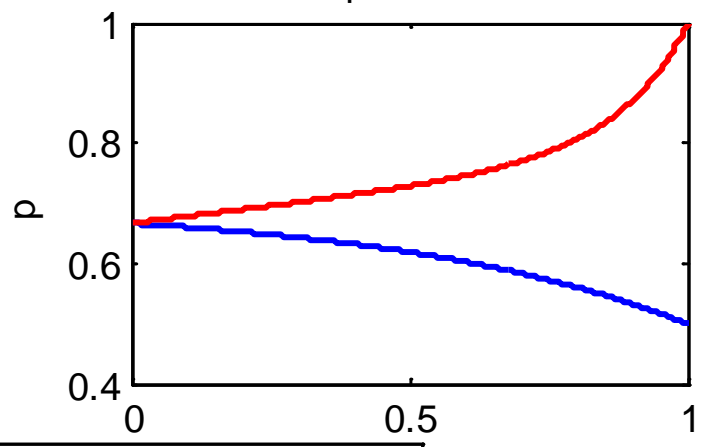


Figure 2: Carbon prices, export tax, import price and fuel demand, as functions of $h$ for $c=0.25$
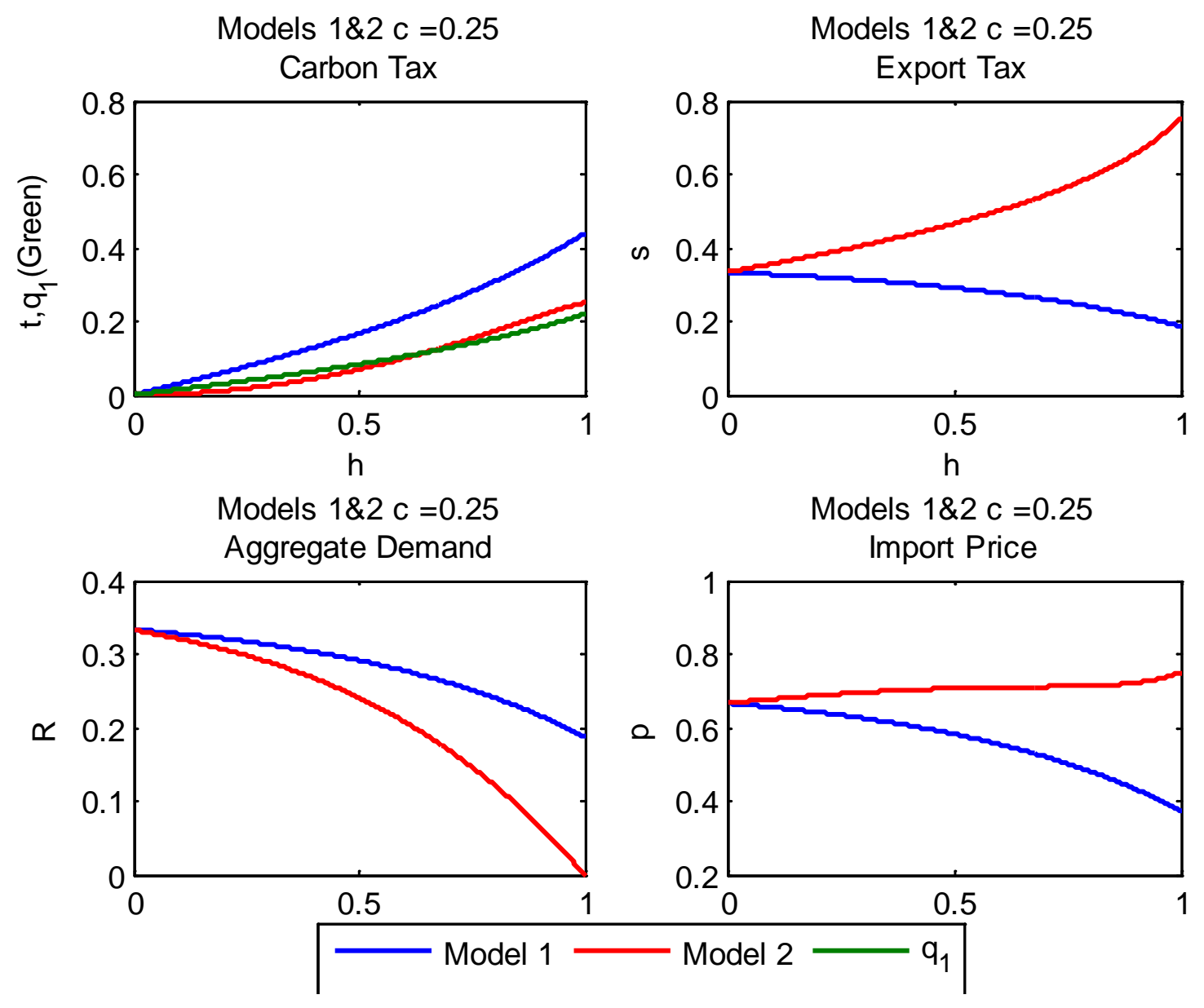
Figure 3: Carbon prices, export tax, import price and fuel demand, as functions of $h$ for $c=0.5$

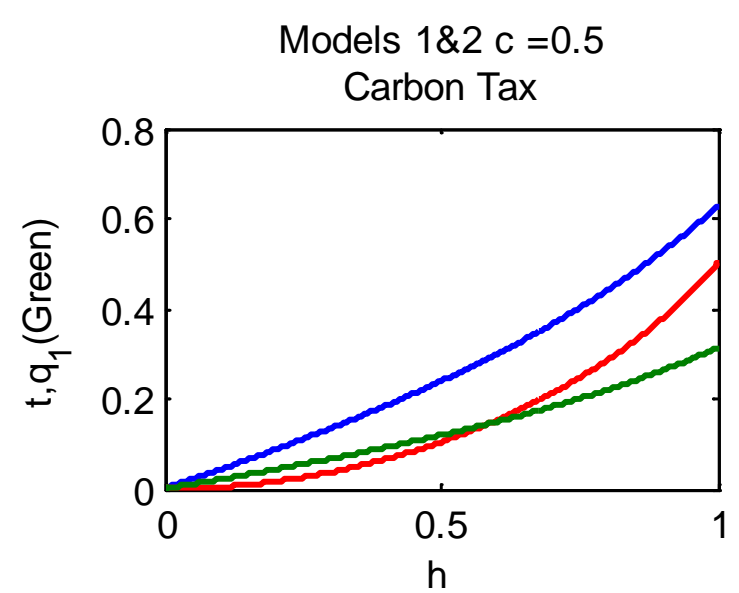

Models $1 \& 2 \mathrm{c}=0.5$

Aggregate Demand

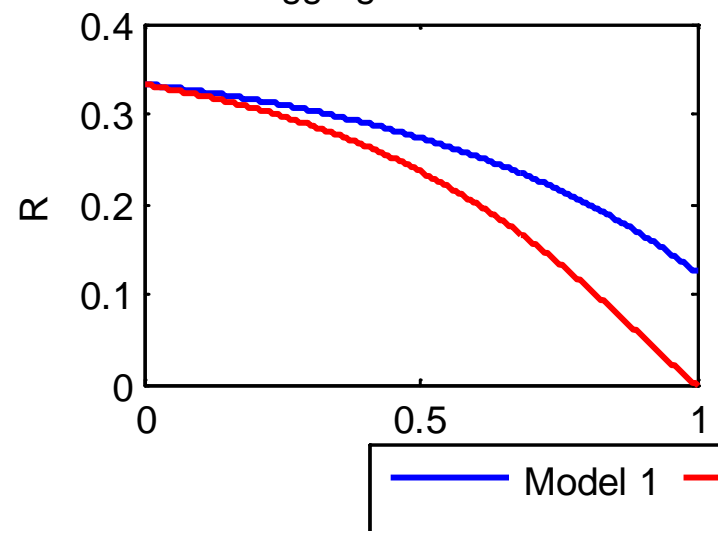

Models $1 \& 2 \mathrm{c}=0.5$

Export Tax

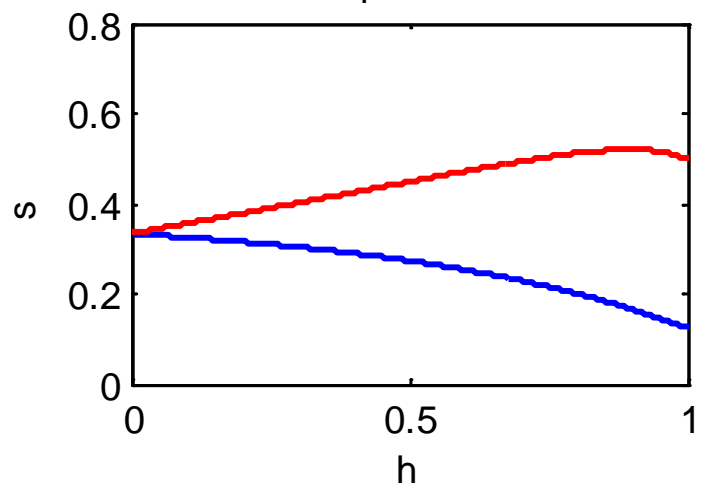

Models $1 \& 2 \mathrm{c}=0.5$ Import Price

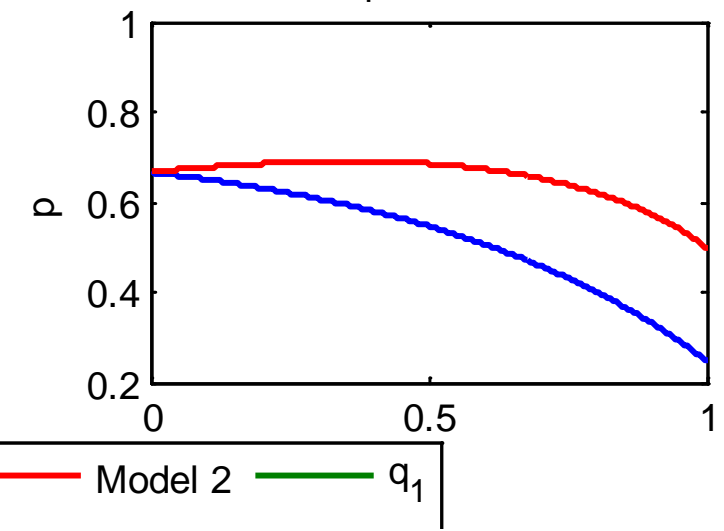


Figure 4: Size of "cap quota” under carbon tax and c-a-t scheme, as function of $h$, for different $c$ values
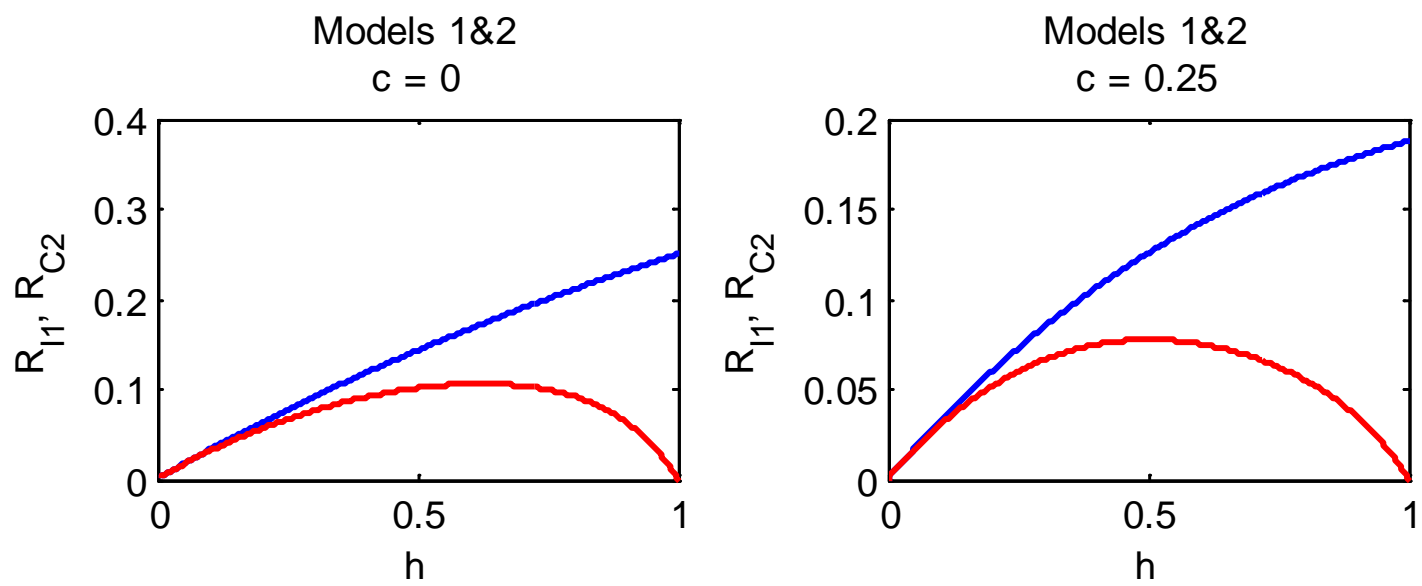

Models $1 \& 2$

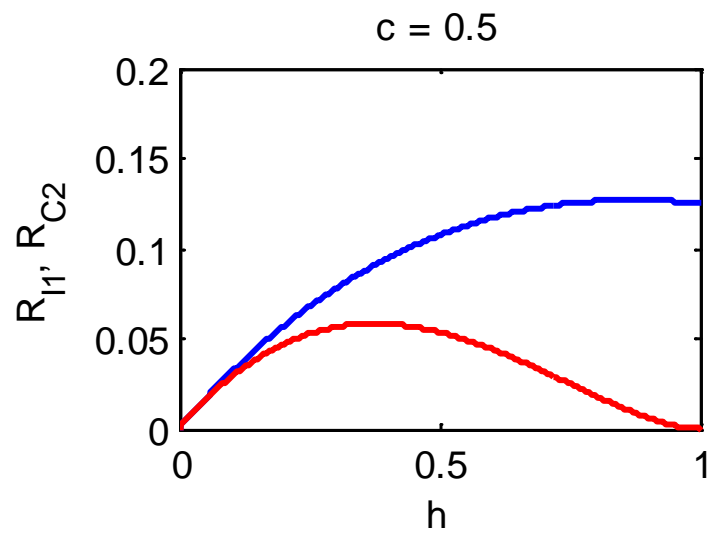

Model $1\left(R_{11}\right)$ Model $2\left(\mathrm{R}_{\mathrm{C} 2}\right)$ 
Figure 5: Welfare of (importer) policy bloc, fringe, and exporter bloc, as functions of $h$, for $c=0$
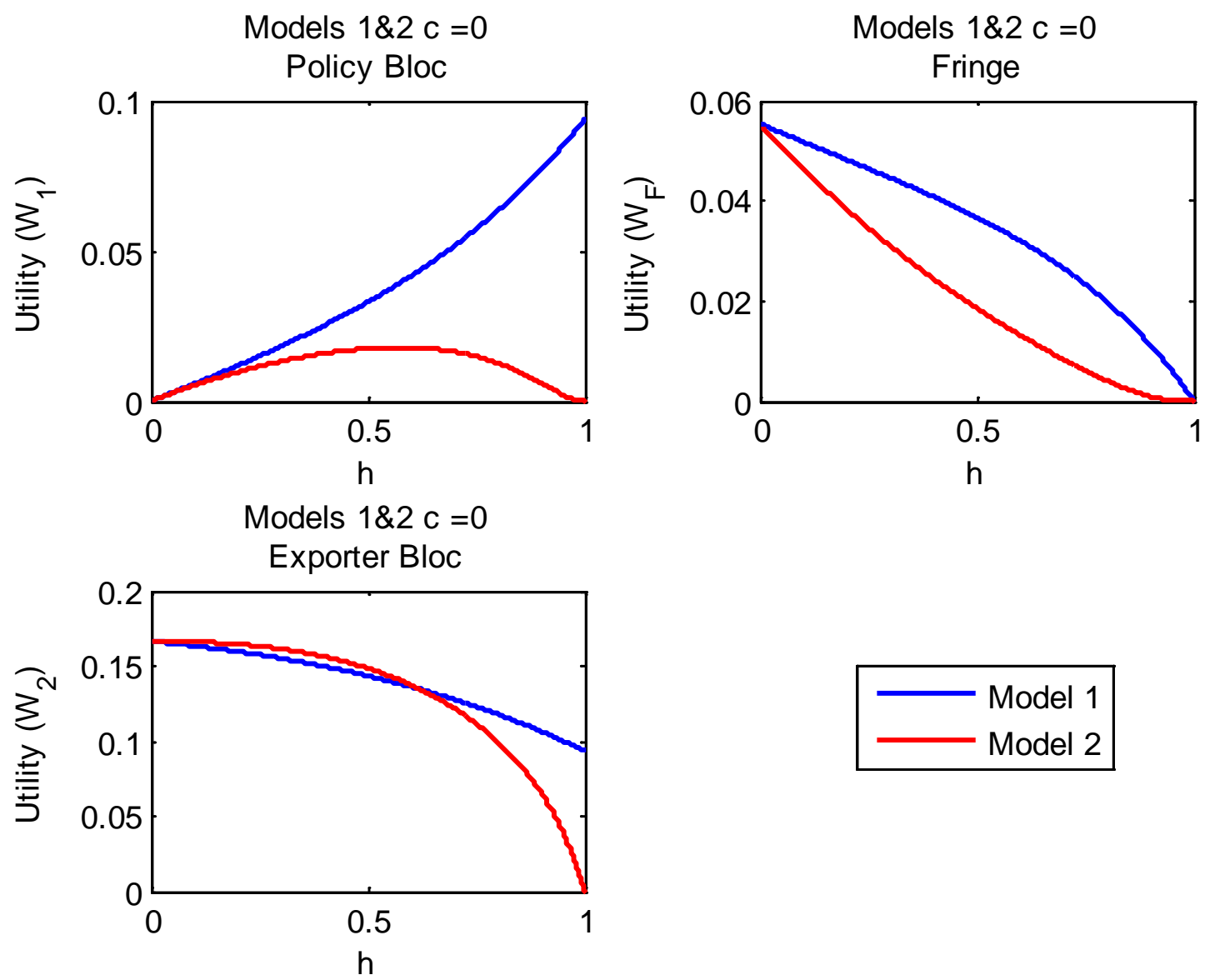
Figure 6: Welfare of importer policy bloc, fringe, and exporter bloc, as functions of $h$, for $c=0.25$
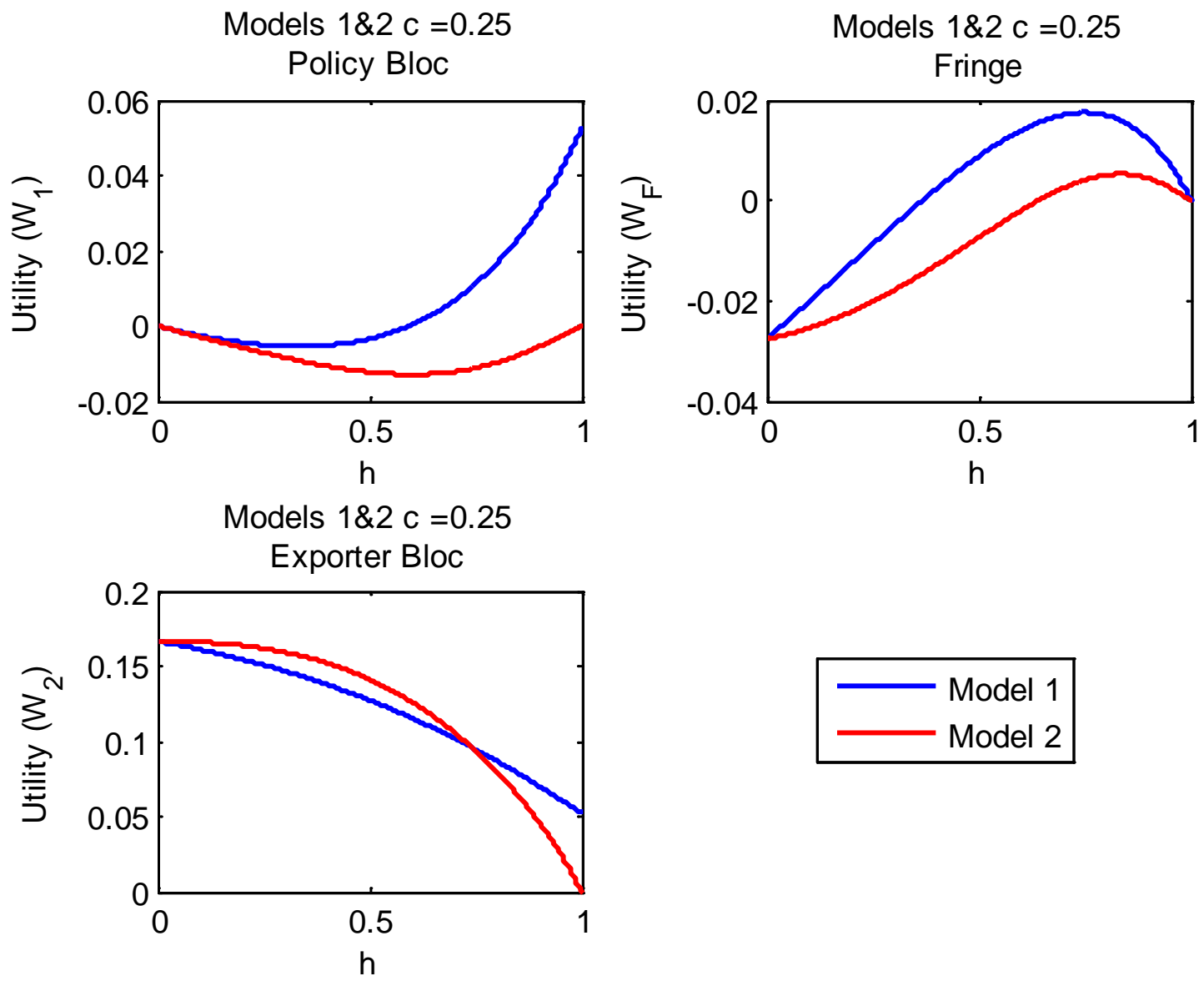
Figure 7: Welfare of importer policy bloc, fringe, and exporter bloc, as functions of $h$, for $c=0.5$
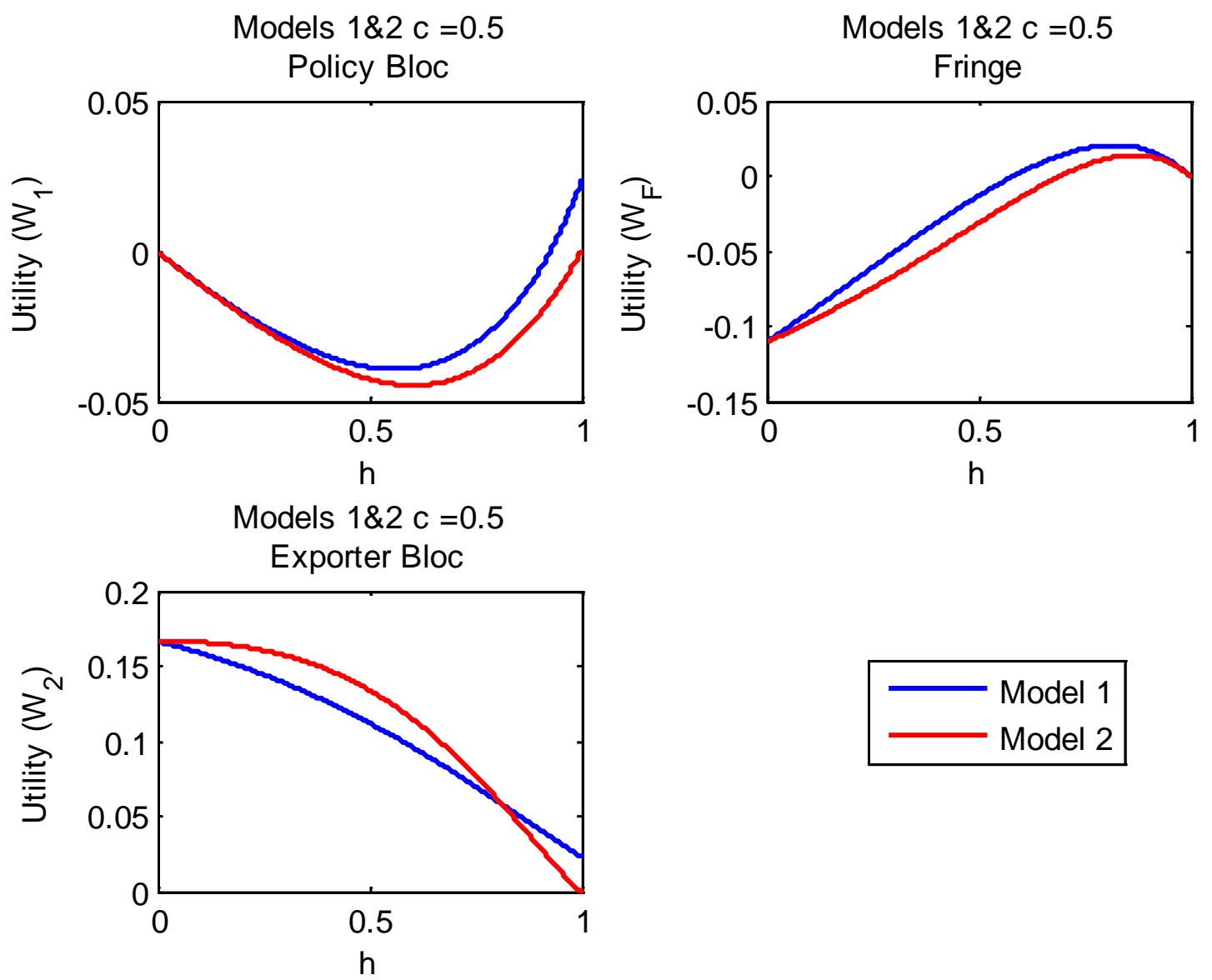
Figure 8: Welfare effect to fringe of offset market under models 1 and 2, for alternative values of $h$ and $c$
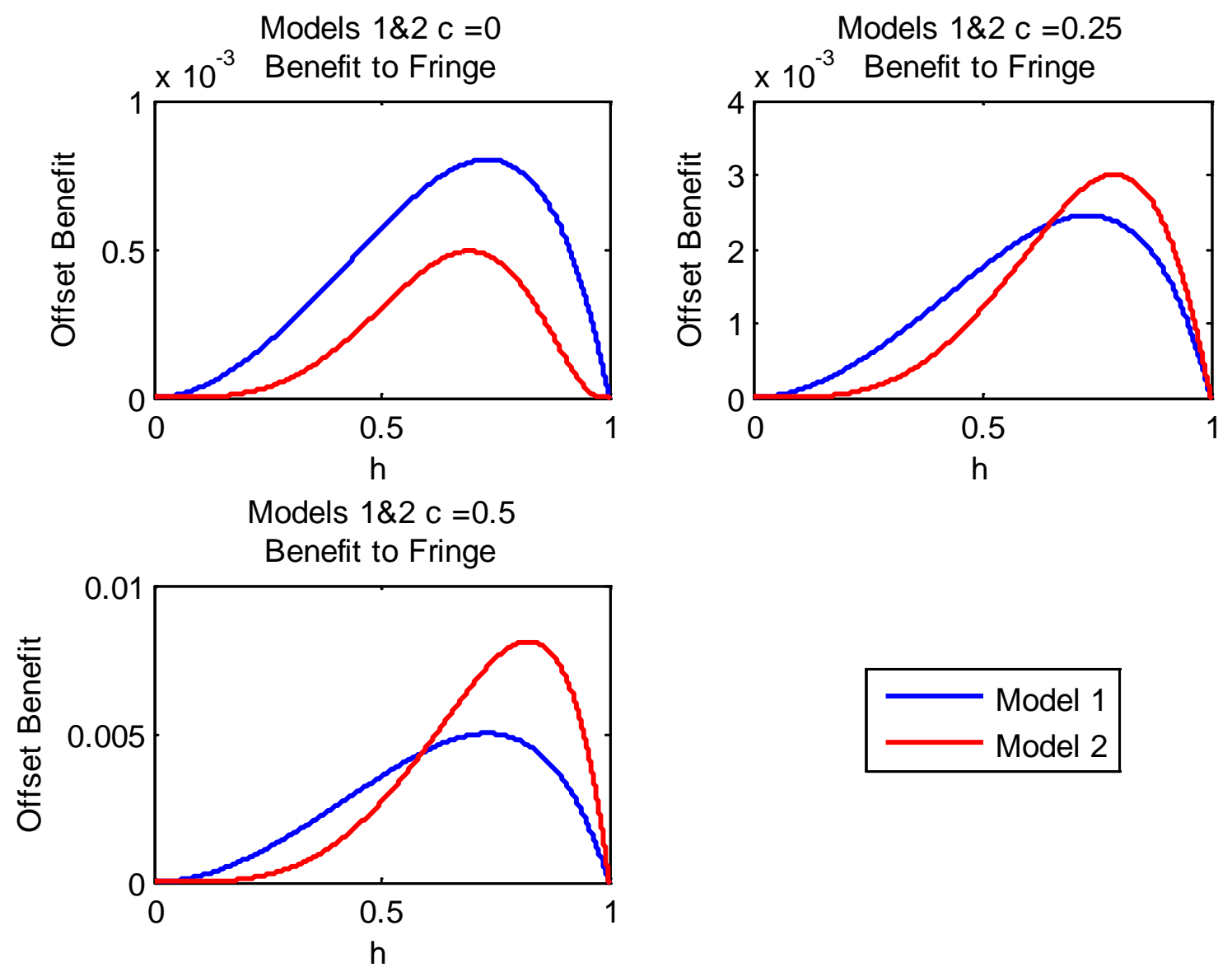


\section{Appendix: Analytical results and proofs}

\section{Proof of Proposition 1:}

Maximizing (1) with respect to $t_{1}$ and $q_{1}$, given (13)-(15), yields the following set of first-order conditions for the policy bloc:

$$
\begin{gathered}
\frac{d W_{1}}{d t_{1}}=\left(1-\gamma_{1} R_{1}-p\right) \frac{\partial R_{1}}{\partial t_{1}}-R_{1} \frac{\partial p}{\partial t_{1}}-h c \frac{\partial R}{\partial t_{1}}=0 \\
\frac{d W_{1}}{d q_{1}}=\left(1-\gamma_{1} R_{1}-p\right) \frac{\partial R_{1}}{\partial q_{1}}-R_{1} \frac{\partial p}{\partial q_{1}}-h c \frac{\partial R}{\partial q_{1}}-2 \frac{1-h}{\gamma} q_{1}=0,
\end{gathered}
$$

where we recognize from (3) that

$$
1-\gamma_{1} R_{1}-p=t_{1}
$$

(A1)-(A2) solve simultaneously for $t_{1}$ and $q_{1}$, and with the respective partial derivatives are found from (13)-(15). Together this yields (17)-(18). Q.E.D.

\section{Proof of Proposition 2:}

The first-order condition for the exporter bloc is

$$
\frac{d W_{2}}{d s}=\left(p-p_{0}-\phi R-c_{2}\right)\left(-\frac{1}{\gamma+\phi}\right)+R \frac{\gamma}{\gamma+\phi}=0,
$$

which yields:

$$
R=\frac{p-p_{0}-c_{2}}{\gamma+\phi}
$$

(13), (14) and (A4) together yield the desired solution, (20). Q.E.D.

\section{Proof of Proposition 4:}

Differentiating (1) with respect to $t$ and $q$ in this case gives the following set of equations:

$$
\begin{gathered}
\frac{d W_{1}}{d t_{2}}=\left(1-\gamma_{1} R_{1}-p\right) \frac{\partial R_{1}}{\partial t_{2}}-R_{1} \frac{\partial p}{\partial t_{2}}-h c \frac{\partial R}{\partial t_{2}}-\frac{(1-h)}{\gamma} q_{2}=0 . \\
\frac{d W_{1}}{d q_{2}}=\left(1-\gamma_{1} R_{1}-p\right) \frac{\partial R_{1}}{\partial q_{2}}-R_{1} \frac{\partial p}{\partial q_{2}}-h c \frac{\partial R}{\partial q_{2}}-\frac{1-h}{\gamma} t_{2}=0 .
\end{gathered}
$$


As before (13)-(15) must be invoked to find partial derivatives. The system (A5)-(A6) constitutes a saddle-point solution, where the partial derivative with respect to $t_{2}$ provides a partial maximum, and the partial with respect to $\mathrm{q}_{2}$ provides a partial (local) minimum, with solution $\mathrm{q}_{2}$ $=0$. Thus (A5), but not (A6), can be invoked to find an optimal solution. (A5) takes the form

$$
t_{2}=-\frac{1-h}{h} q_{2}+\frac{h \gamma}{(\gamma+\phi)^{2}-h^{2} \phi^{2}}\left\{\phi\left(1-p_{0}-s\right)+(\gamma+\phi) c\right\}
$$

(A7) solves alone for $t_{2}$, observing also $\mathrm{q}_{2} \leq \mathrm{t}_{2}$ ( $\mathrm{q}_{2}$ cannot exceed $\mathrm{t}_{2}$ since all realized offsets must have cost less than or equal to $\mathrm{t}_{2}$ ). Optimality then requires that $\mathrm{q}_{2}$ (= marginal cost of energy abatement in the fringe) be set at its highest possible level $=t_{2}$. Setting $q_{2}=t_{2}$ we find (24).

(25) is found realizing that both the policy bloc and fringe face a marginal energy cost of $p+t_{2}$, which must be the marginal energy productivity in both regions. Q.E.D.

\section{Proof of Proposition 5:}

We solve (12) and (26) for $\mathrm{p}$ and $\mathrm{R}$ to yield

$$
\begin{aligned}
& p=\frac{1}{\gamma+(1-h) \phi}\left[\gamma\left(p_{0}+s\right)+\gamma \phi R_{P}+(1-h) \phi\right] \\
& R=\frac{\gamma}{\gamma+(1-h) \phi} R_{P}+\frac{1-h}{\gamma+(1-h) \phi}\left(1-p_{0}-s\right)
\end{aligned}
$$

The exporter takes (A8)-(A9) and $\mathrm{R}_{\mathrm{P}}$ as given, and faces the following responses to changes in s:

$$
\frac{\partial p}{\partial s}=\frac{\gamma}{\gamma+(1-h) \phi}, \frac{\partial R}{\partial s}=-\frac{1-h}{\gamma+(1-h) \phi} .
$$

This yields the following condition for the exporter's optimal strategy in this case:

$$
\frac{d W_{2}}{d s}=\left(p-p_{0}-\phi R-c_{2}\right)\left(-\frac{1-h}{\gamma+(1-h) \phi}\right)+R \frac{\gamma}{\gamma+(1-h) \phi}=0,
$$

with the corresponding optimal condition on R:

$$
R=\frac{1-h}{\gamma+(1-h) \phi}\left(p-p_{0}-c_{2}\right) .
$$

The exporter considers $\mathrm{R}_{\mathrm{P}}$ as exogenous. $\mathrm{R}_{\mathrm{P}}$ is still set optimally by the policy bloc, as part of the market equilibrium, with $t_{2}$ as the equilibrium emissions quota price. $\mathrm{R}$ and $\mathrm{p}$ are still determined by (13)-(14). We then find $\mathrm{s}, \mathrm{p}$ and $\mathrm{R}$ as functions of $\mathrm{t}_{2}$ and $\mathrm{q}_{2}$, and in particular, (27). Q.E.D. 